\title{
REPENSANDO O MÉTODO CASO EM CURSOS DE ADMINISTRAÇÃO: DESAFIOS E OPORTUNIDADES \\ DA ABORDAGEM SOCIOCONSTRUTIVISTA \\ COM FERRAMENTAS DA WEB 2.0
}

\author{
Marcos Lima* \\ Thierry Fabiani**
}

\section{RESUMO}

Este artigo discute as origens e os usos do Método Harvard de estudos de casos em educação empresarial. Ele argumenta que os princípios socioconstrutivistas incorporados nesta técnica de ensino são mais relevantes em nossa sociedade pósmoderna do que na era industrial em que ela foi concebida. Recentes evoluções tecnológicas, principalmente com advento da Web 2.0 e ferramentas colaborativas on-line, tornam oportuno experimentar com versões de estudos de caso mediadas por interfaces digitais, a fim de aumentar o seu potencial de pensamento crítico e criativo em ambientes autênticos - o que denominamos potencial de "Interatividade Colaborativa". Após analisar cuidadosamente os méritos pedagógicos da abordagem original, discutimos possíveis inovações para versões de casos na web que poderiam ser incorporadas a essa tradição centenária. Apresentamos os resultados de nossas experiências anteriores no Brasil com o Sistema Panteon para resolução colaborativa de problemas (LIMA, 2003), bem como uma utilização mais recente do Facebook e Google Sites como ferramentas para a discussão de um caso fictício chamado "Organixis" na EMLV, uma Escola de Gestão em Paris. Conclui-se que, se por um lado essas ferramentas têm um enorme potencial em termos de interatividade colaborativa, por outro lado várias barreiras se apresentam, incluindo a resistência de professores e alunos a novos métodos baseados em aprendizagem à distância e os desafios tecnológicos de gestão de plataformas on-line.

Palavras-chave: Estudos de caso. Ensino de gestão. Interfaces digitais.

\section{ABSTRACT \\ RETHINKING THE CASE METHOD OF BUSINESS COURSES: CHALLENGES AND OPPORTUNITIES OF THE SOCIO-CONSTRUCTIVIST APPROACH WITH TOOLS OF WEB 2.0}

This article discusses the origins and current uses of Harvard's Case Method in business education. It argues that the socio-constructivist principles embedded in this teaching

\footnotetext{
* Doutor em Tecnologias de Comunicação Aplicadas ao Ensino de Gestão pela Universidade Federal da Bahia (UFBA). Professor adjunto e chefe do departamento de empreendedorismo da École de Management Léonard de Vinci / PULV. Pesquisador no De Vinci Business Lab, em Paris. marcos.lima@devinci.fr

** Doutor em Gestão pela Euromed Business School. Professor adjunto da École de Management Léonard de Vinci / PULV. Pesquisador do De Vinci Business Lab, em Paris. Professor da Universidade da Córsega. thierry.fabiani@devinci.fr
} 
technique are more relevant in our post-modern society than it was in the industrial age when it was first conceived. Recent changes in technology, particularly with the advent of Web 2.0 online collaborative communities, suggest that it is time to experiment it with case studies mediated by digital interfaces in order to increase its critical and creative thinking potential in authentic problem environments (what we call "Collaborative Interactivity" potential). After a careful analysis of the pedagogical merits of the original approach, we discuss possible Web 2.0 innovations that could be built into this centennial tradition. We present the findings from our previous experiments in Brazil with the Panteon System for collaborative problem solving (LIMA, 2003), as well as a more recent use of Facebook and Google Sites as tools to discuss a fictitious case called "Organixis" at EMLV, a Business School in Paris. We conclude that while these tools have an enormous potential in terms of supporting collaborative interactivity, several barriers remain, including the resistance from both teachers and students to new methods based on distance learning and technological challenges of managing online platforms.

Keywords: Case studies. Management education. Digital interfaces.

\section{Introdução}

A importância do diálogo para fomentar o pensamento crítico e criativo é reconhecida há pelo menos 24 séculos, desde quando Sócrates demonstrou como sua abordagem maiêutica poderia ser uma forma eficaz de aprender através de discussões. Este princípio pedagógico básico foi redescoberto há quase um século, no domínio das ciências de gestão, com o método de estudo de casos proposto pelos pioneiros da Harvard Business School. O presente artigo discute como os casos tipo Harvard promovem a colaboração e reflexão em torno de problemas de gestão autênticos e especula sobre como a interatividade e colaboração inerentes às tecnologias baseadas na web podem reforçar certas competências do pensamento crítico e criativo.

Após apresentar a tradição de casos Harvard, o artigo discute brevemente dois experimentos que apresentam tanto potencialidades como limites das novas mídias como interfaces para a aprendizagem baseada em casos. O primeiro experimento foi o produto de uma das teses de doutorado de um dos autores na UFBA (LIMA, 2003), a interface Panteon. Criado no início dos anos 2000, quando as mídias sociais e ferramentas da Web 2.0 ainda não estavam disponíveis, o Panteon é um sistema que permite a estudantes de administração analisar problemas organizacionais a partir de múltiplas perspectivas, navegando esses problemas de uma forma não linear. A plataforma facilita processos de metacognição e o desenvolvimento de soluções colaborativas.

A segunda experiência, mais recente, usa princípios semelhantes. Baseado em mídias sociais e recursos da web modernos, um projeto piloto foi criado através de uma combinação de recursos como Google Sites, Youtube e Facebook. Esse estudo de caso interativo permitiu a vários autores criar conteúdo on-line e enriquecê-lo com vídeos e imagens disponíveis na web. Além disso, o sistema facilitou a colaboração (através de comentários, links, tags etc.) entre os alunos usando mídias sociais. O caso, que intitulamos "Organixis", descreve uma empresa de software fictícia que cria jogos para telefones celulares. Os estudantes tiveram duas semanas para percorrer as dezenas de páginas web hospedadas no serviço Google Sites. Essas páginas descrevem as várias funções da empresa e os problemas encontrados. Em seguida, solicitou-se dos estudantes que colaborassem à distância em fóruns específicos de discussão que foram criados usando uma página no Facebook. Os alunos foram encorajados a compartilhar ideias, materiais adicionais relativos a questões específicas ou problemas, links e vídeos no âmbito desse fórum. Após um dia inteiro de workshops para discutir o caso "Organixis", entrevistamos alunos e professores a fim de compreender melhor como se sentiam sobre os elementos de aprendizagem ativa embutidos nesta pedagogia, sobre o seu potencial e deficiências. 
Como resultados preliminares desses dois experimentos (separados por quase dez anos), apresentamos elementos empíricos indicando que, se por um lado os ambientes de mídia interativa podem ajudar a promover o pensamento crítico e criativo em estudantes da "geração net", por outro lado existem várias barreiras à adoção dessas ferramentas, tanto na perspectiva dos professores quanto na dos alunos.

$\mathrm{O}$ artigo está dividido em três partes. Na primeira, apresenta-se o método caso tradicional e os seus princípios socioconstrutivistas. Esta é a base sobre a qual versões mais modernas da abordagem caso podem ser desenvolvidas. Discute-se, em seguida, como os processos de raciocínio crítico e criativo são ativados com o método caso. Na última parte, apresentamos os protótipos Panteon e da simulação "Organixis", e como elas foram utilizadas no Brasil e na França, antes de discutir os resultados e as implicações de nossas experiências com essas ferramentas.

\section{O Método caso em Cursos de Gestão}

O método caso é uma pedagogia de aprendizagem ativa baseada na análise racional de situações reais (BRULHART, 2009). Trata-se de uma abordagem que estimula os alunos a analisar e discutir tais situações usando as informações disponíveis. De acordo com um dos pioneiros do método caso, Gragg (1954, p. 34), um caso em gestão é

[...] um registro de um episódio no mundo dos negócios ao qual foram confrontados executivos reais, acompanhado do contexto gerencial correspondente, assim como fatos, opiniões e premissas necessários à tomada de decisão. Estes casos reais são apresentados aos alunos para análise, discussão aberta e decisão final quanto ao tipo de ação que deve ser tomada.

Naumes e Naumes (2012, p. 12) definem um caso simplesmente como "uma descrição factual de eventos que aconteceram em algum momento no passado". Histórias fictícias, de acordo com eles, não têm o mesmo rigor intelectual de um caso com base em pesquisa factual. Em uma edição anterior de seu The Art and Craft of Case Writing, de 1999, os autores explicam que
Os estudos de caso fornecem um meio pelo qual os leitores podem aprender através da discussão de situações e circunstâncias factuais, seguindo as ações e processos de decisão de pessoas reais, confrontados com problemas autênticos, em situações verídicas. Trata-se de uma abordagem heurística, em que não pode haver uma 'melhor resposta', contrariamente aos modelos algorítmicos [das ciências exatas]. Os alunos ficam muitas vezes desconfortáveis com esse caráter ambíguo, essa ausência de uma única 'resposta correta'. Em um caso, avaliar a situação ou tomar uma decisão muitas vezes é tão importante quanto se familiarizar com as especificidades do contexto. A partir da análise de uma série de casos, os alunos desenvolvem a capacidade de aplicar conceitos e extrapolar teorias subjacentes às situações com que se depararão no futuro. (NAUMES; NAUMES, 1999, p. 47, grifo do autor).

Essas definições correspondem ao que se tornou conhecido como o caso clássico "tipo Harvard", em razão de aquela instituição ter sido a primeira a popularizar tal abordagem. Um caso "tipo Harvard" nunca inclui conclusões, deixando o papel de fazer inferências inteiramente aos leitores (ELLET, 2007). O método é considerado particularmente indicado à preparação de alunos para lidar com problemas não estruturados ou pouco estruturados, aos quais é necessária uma abordagem intuitiva como acontece tipicamente no domínio das ciências sociais.

O termo "caso" é interpretado de forma diversa em diferentes contextos. A seguir, algumas distinções úteis (DHAR; DHAR, 2007):

- método caso - processo de escrita e de ensino com base em situações organizacionais da vida real, normalmente seguindo as diretrizes do estilo Harvard;

- estudo de caso - texto utilizado no método caso;

- caso de pesquisa - um método de investigação qualitativa que envolve coleta e compilação de vários casos em diferentes contextos para encontrar pontos em comum e tirar conclusões acadêmicas sobre um fenômeno;

- caso de gestão - geralmente, uma breve descrição de algumas práticas de administração para consolidar conceitos específicos ou 
ilustrar situações e provocar uma discussão rápida ou análise superficial;

- "caselet" - um caso de gestão particularmente curto.

Os casos que seguem as orientações da tradição Harvard geralmente enfatizam as seguintes características (ABELL, 1997):

- apresentam um ou mais problemas de gestão a serem solucionados por meio de discussão;

- lidam com temas relevantes;

- levantam controvérsias que podem dar origem a diferentes interpretações, decisões e planos de ação;

- oferecem contrastes e comparações;

- $\quad$ permitem que os alunos transplantem lições e conceitos subjacentes ao processo para outras situações;

- contêm informações úteis para apreender questões típicas de um setor, tais como a descrição dos produtos, indústrias e pessoas envolvidas, usando dados qualitativos e quantitativos;

- apresentam um estilo de narrativa bastante pessoal, incluindo os pontos de vista dos participantes e suas declarações e descrições de processos organizacionais formais e informais;

- são bem estruturados, geralmente contendo uma introdução seguida de exploração do contexto e apresentação do dilema ou decisões a serem tomadas;

- contêm entre dez e vinte páginas de texto e até cinco páginas de anexos.

O estilo de escrita de um caso deve ser neutro e atraente. O tempo passado é usualmente empregado. O nome original da empresa e os personagens envolvidos podem ser alterados para preservar o anonimato, mas há uma grande ênfase em refletir situações reais. Um caso Harvard deve ser acompanhado de notas de ensino detalhadas, que permanecem inacessíveis aos alunos, contendo indicações sobre a forma como o caso pode ser usado e sugerindo ao professor abordagens para fomentar a discussão e análise.

Casos geralmente não são lineares ou simplistas, tentando assim reproduzir a complexidade de informações da vida real. De acordo com Jackson (2011, p. 147):

Contrariamente aos livros didáticos, caracterizados por uma estrutura lógica e coerente em sua apresentação, os casos tentam introduzir mais realismo - adicionando incerteza, fluidez narrativa e situações contingenciais. Assim, muitos casos têm uma tendência à complexidade, contendo 'ruídos informacionais' (irrelevâncias, becos sem saída, testemunhos equivocados ou tendenciosos por personagens do caso), omissões que devem ser inferidas, uma estrutura não-linear com elementos essenciais espalhados ao longo do texto ou muitas vezes disfarçados.

O método caso (originalmente chamado de "método de problema") foi concebido e implementado em 1870 por Christopher Columbus Langdell, decano da Faculdade de Direito de Harvard. A premissa básica era a de que os estudantes de Direito deveriam ser capazes de aprender fazendo, e que as discussões em sala de aula dariam substância e conteúdo a esse processo de aprendizagem (DHAR; DHAR, 2007). Langdell criou o primeiro compêndio de casos a partir de uma série de episódios legais compilados. Adepto da maiêutica, ou o "método socrático", ensinava por perguntas. Ele questionava os alunos sobre o caso, suas doutrinas e princípios subjacentes, seus principais pontos e como cada situação se comparava com outros casos. A preparação para as aulas envolvia mais do que simplesmente memorizar fatos e recitá-los; estudantes eram obrigados a discutir, interpretar e analisar o caso, algo inovador para a época.

A reação inicial foi bastante negativa, enfrentando a resistência tanto de alunos quanto de professores. Em 1920, no entanto, o método tornou-se a principal ferramenta pedagógica no ensino jurídico em Harvard (JACKSON, 2011). Ao adaptar os casos para o mundo da gestão no início do século $\mathrm{XX}$, professores de Harvard focaram-se em como transformar fatos organizacionais e suas implicações em fonte de discussão em sala de aula. Melvin Copeland, professor de marketing, tornou-se o primeiro a compilar um livro de casos de negócios, em 1921 (WILLIAMSON, 2012).

O recente aumento da popularidade dos estudos de caso é devido em grande parte à explosão de escolas de gestão e programas de MBA em todo o mundo, bem como a facilidade de acesso às prin- 
cipais bases de dados de casos disponíveis através da Internet. Harvard continua a ser o epicentro da produção e distribuição dos casos em todo o mundo, mas outros centros muito prolíficos surgiram em países como Inglaterra, França e Índia.

Vários autores (DHAR; DHAR, 2007; HEATH, 2006; SKUDIENNE, 2012; SRINIVASAN et al, 2005) sistematizaram os benefícios pedagógicos do método caso. Algumas de suas virtudes incluem:

- aplicação do conhecimento gerencial em decisões e planos de ação;

- aquisição de um senso de autocontrole sobre o processo de aprendizagem;

- $\quad$ experimentação de diferentes situações num mesmo contexto ou, inversamente, a mesma situação em contextos diferentes;

- desenvolvimento do hábito da leitura em profundidade;

- $\quad$ adoção de uma abordagem mais dinâmica / interativa de aprendizagem;

- estímulo para que os alunos questionem seus axiomas e pressuposições;

- desenvolvimento de competências de comunicação e apresentação em público;

- redução do fosso entre teoria e prática;

- uso de dados qualitativos e quantitativos para discutir cenários gerenciais;

- $\quad$ prática da tomada de decisão;

- desenvolvimento de um senso de confiança e responsabilidade por suas intervenções;

- exercício da virtude de ouvir antes de falar;

- ponderação de diferentes cursos decisórios antes de agir;

- manipulação de opiniões e inferências;

- apresentação de perspectivas e pontos de vista;

- uso de ferramentas, modelos de análises (frameworks) como "check-lists conceituais".

Casos invertem a configuração típica da aula magistral, em que o professor fala o tempo todo. Em um bom ambiente de caso, o professor é um mero facilitador e deve se expressar muito menos do que os alunos. Os estudantes são obrigados a pensar e a participar, eles são convidados a tomar decisões e desenvolver soluções, e, ao fazê-lo, acabam por desempenhar o papel dos futuros gestores que vão se tornar.
A literatura sobre as competências desenvolvidas pelo método caso é vasta (BRULHART, 2009; PILKIENE, 2012; PITT et al, 2012). Sabe-se que os casos estimulam um comportamento similar ao de gestores reais, incentivando estudantes a considerar cenários alternativos, desenvolver seu senso de autonomia e favorecer a atitude de colaboração. O método leva os professores a descer de seu púlpito, saindo do seu papel de "fonte de conhecimento" para assumir uma atitude muito mais relevante de provocador de discernimento e mediador de descobertas. Para resumir, nas palavras de Dhar e Dhar (2007, p. 88),

Em vez de ouvir ou ler as regras gerais de alguma fonte não examinada de autoridade, aceitá-los e, em seguida, esperar que os alunos captem os seus princípios, estudos de caso fornecem uma excelente oportunidade para desenvolver a confiança na análise de situações e resolução de problemas.

Pode-se facilmente constatar, na literatura, como os casos abordam todas as dimensões da taxonomia de objetivos educacionais de Bloom (1956 apud PITT et al, 2012):

- Conhecimento: a exposição a diferentes situações em diversos domínios de problemas ajuda os alunos a se familiarizar com as melhores práticas em determinados setores, com estruturas e terminologias específicas.

- Compreensão: mais do que simplesmente reunir informações e conhecimento, discussões de casos levam à compreensão de como certas decisões são tomadas, como as categorias em um modelo ou estrutura se inter-relacionam, como certas abordagens são mais ou menos arriscados e quais são as competências necessárias para desenvolver julgamento justo.

- Aplicação: a aplicação imediata dos princípios de raciocínio ou modelos de análise em situações concretas de negócios é talvez uma das qualidades mais visíveis do método caso.

- Análise, síntese e avaliação: estas competências fazem parte das habilidades críticas e criativas de pensamento que são necessários para transformar informação em conhecimento acionável. Os detalhes sobre essas competências cognitivas e como eles 
são estimulados pelo estudo de caso serão discutidos mais adiante.

\section{Elementos Socioconstrutivistas dos Estudos de Caso}

Do ponto de vista pedagógico, o método Harvard pertence ao paradigma socioconstrutivista: é realista, interativo, contingente, crítico e indutivo (LIMA, 2003; SKUDIENE, 2012). Cada uma destas características é descrita em mais detalhe a seguir:

- Realista: esta característica é consistente com o princípio construtivista de autenticidade situacional. Segundo esse princípio, os alunos sentem-se mais legítimos quando lidam com fatos que refletem a realidade.

- Interativo: a fim de resolver os estudos de caso, os alunos devem colaborar entre si e com o professor. Isso favorece o contraste de opiniões e uma construção intersubjetiva de planos de ação que refletem a maneira como os tomadores de decisão geralmente trabalham em organizações modernas.

- Contingente: a profundidade da análise e as discussões dependem do nível dos alunos, a sua experiência profissional, sua formação cultural e sua familiaridade com o método caso. Não há uma "melhor solução", mas sim argumentos mais ou menos consistentes e propostas com base no nível de maturidade dos alunos.

- Crítico: o método caso não é sobre o que pensar, mas como pensar. Como será discutido brevemente, estudos de caso estimulam os alunos a discutir de forma construtiva, analisar de forma sistêmica, comparar, questionar e avaliar. Existem vários prós e contras de cada argumento.

- Indutivos: casos são, por natureza, baseados em situações particulares que podem ou não ser generalizadas. Em vez de impor teorias "de cima para baixo" (top-bottom, abordagem dedutiva), o método caso favorece a observação e o uso de questões que levam à descoberta individual e colaborativa.

A essência do socioconstrutivismo é o que Lima (2003) chamou de "Interatividade Colaborativa", uma expressão que enfatiza os dois elementos básicos dessa abordagem. Baseia-se nos seguintes pressupostos pedagógicos:

a) O conhecimento é construído na mente do aprendiz, o que significa que ele pode ser estimulado através da comunicação de informações e dados estimulantes, percebidos como relevantes pelo aprendiz;

b) A construção do conhecimento é em grande parte o resultado da manipulação simbólica, o que significa que a aprendizagem muitas vezes requer interação proativa com objetos informacionais;

c) Essa interação é mais rica quando ocorre não só entre o indivíduo e o objeto, mas também entre os indivíduos que compartilham os seus conhecimentos;

d) O conhecimento está profundamente enraizado no contexto em que as ações ocorrem.

Como corolário dessas premissas, temos que: a) existem múltiplas perspectivas do mundo; b) a aprendizagem é impulsionada por situações-problema de grande significado para o aluno; c) a aprendizagem requer articulação e representação do conhecimento; d) o significado das mensagens deve ser socialmente negociado e compartilhado (JONASSEN et al, 1999).

Se essas premissas são aceitas como válidas, os alunos devem ter quatro condições interdependentes, a fim de "construir o conhecimento", quais sejam: o processo de aprendizagem deve encorajar a manipulação simbólica do objeto de estudo (interação); deve haver discussão constante entre os alunos para incentivar a partilha de suas ideias (colaboração); os alunos devem ser encorajados a pensar de forma crítica e criativa sobre suas interações individuais com os objetos, assim como suas colaborações com colegas (reflexão); $\mathrm{e}$, finalmente, todo esse processo de aprendizagem deve ocorrer em um ambiente de informação que é autêntico, relevante e complexo (contextualização). Assim, a Interatividade Colaborativa pode ser entendida como a construção do conhecimento com base na manipulação autorregulada de conceitos e informações que envolvem a reflexão individual e colaboração em um contexto autêntico. A Figura 1 ilustra esse conceito. 
Figura 1 - Conceito de Interatividade Colaborativa

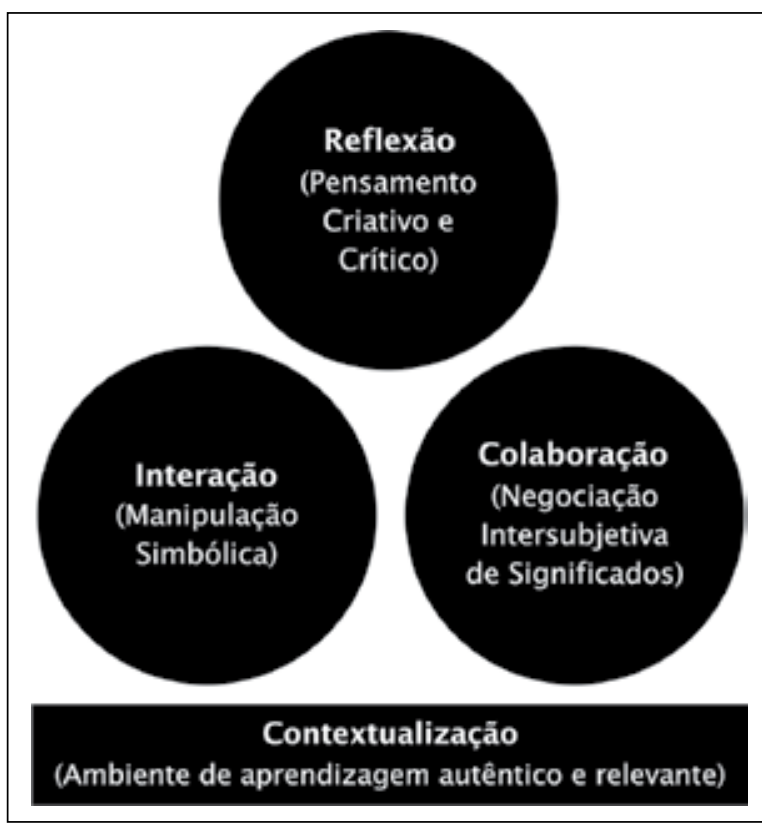

Fonte: Adaptado de Lima (2003, p. 87).

No processo de criação de conhecimento, a manipulação de objetos informacionais (sejam empíricos ou conceituais) é também conhecida simplesmente como learning-by-doing (aprender fazendo) ou learning-by-exploring (aprender explorando). $\mathrm{O}$ conhecimento tácito é difícil de ser codificado e, portanto, requer participação social e experimentação para ser internalizado. De acordo com os resultados de um experimento bem conhecido (SPENCER, 1991), as pessoas lembram-se de apenas cerca de $10 \%$ do que leem, $20 \%$ do que ouvem, $30 \%$ do que veem, $50 \%$ do que veem e ouvem, $70 \%$ do que eles falam durante uma palestra e $90 \%$ do que elas dizem ao executar ações relacionadas ao conteúdo do discurso. Jonassen e colaboradores (1999) sugerem que devemos, portanto, estimular os alunos a organizar as suas próprias informações, para gerar hipóteses e testá-las a fim de internalizar o conhecimento resultante. Quando eles simplesmente recebem e reprocessam as informações fornecidas pelo professor, o seu nível de envolvimento com o contexto informacional é muito inferior.

Quanto à dimensão "colaboração", sabe-se por experiência que as discussões de grupo são uma parte essencial do seu processo de aprendizagem. Lucena e Fuks (2000) sugerem que através da cola- boração alunos podem compartilhar uma variedade de estratégias de aprendizagem complementares no processo de resolução de problemas. Isto acontece, de acordo com Greer e colaboradores (2000), porque a colaboração coloca os indivíduos na posição de ter que explicar e convencer os outros sobre seus próprios processos cognitivos, o que facilita a metacognição ("saber o que se sabe" ou "aprender como se aprende"). Um benefício fundamental deste processo colaborativo são as múltiplas perspectivas inerentes às discussões. Em domínios de conhecimento pouco estruturados, como as ciências sociais, utilizar diferentes pontos de vista é uma estratégia adequada para reconstruir uma realidade intersubjetiva.

O terceiro elemento, "a reflexão crítica e criativa", é uma consequência natural de ambos os processos mencionados acima (colaboração e interação). De fato, de acordo com a perspectiva construtivista adotada aqui, a construção do conhecimento ocorre quando os alunos têm a oportunidade de aplicar suas estruturas mentais para um objeto ou problema específico, resultando em ajustes na sua estrutura mental (TOBIN, 2000). Embora este processo possa ser enriquecido com a contribuição intersubjetiva de outros observadores, é importante que os estudantes formem uma opinião individual, pessoal do problema antes de participar na discussão em grupo. Assim, Sandholtz (1996) sugere que, em muitos casos, um professor pode ser mais eficaz fazendo perguntas provocativas ao invés de fornecer respostas, particularmente em áreas de conhecimento pouco estruturadas como as ciências sociais. Este é o princípio básico do já mencionado método milenar do diálogo socrático: levar o aluno à descoberta de nuances nos fenômenos observados, através de provocações intelectuais.

Ao contrário dos elementos interação, colaboração e reflexão, a contextualização não é uma atividade, mas uma qualidade inerente ao ambiente de aprendizagem baseado em Interatividade Colaborativa. Pesquisas mostram que a aprendizagem pode ser mais eficaz quando ocorre em um contexto mais próximo da realidade vivida pelo aluno em sua vida profissional ou quotidiana (JONASSEN et al, 1999; MASETTO, 2001; MATTA, 2001). Selinger (2001) define como autênticas as tarefas que 
os alunos reconhecem como relevantes de acordo com as suas experiências anteriores. Deve-se ter o cuidado de criar situações-problema que emulem o ambiente profissional passado ou futuro. $\mathrm{O}$ fato de os alunos estarem em contato com a sua realidade profissional é altamente motivador. Essa autenticidade ajuda a dar sentido às teorias e conceitos que eles devem aprender e ajuda a integrar esse conhecimento em suas estruturas intelectuais. Problemas autênticos colocam os alunos em contato com o mundo dos praticantes, que estão envolvidos em situações específicas da vida real.

Young (1995) enfatiza dez atributos essenciais ou problemas do "mundo real" que devem ser respeitados em contextos de aprendizagem autêntica: 1) a solução de tais problemas deve solicitar a coordenação de vários processos cognitivos, tais como análise, planejamento, identificação de problemas e metacognição; 2) o contexto deve estimular percepções críticas sobre situações viáveis; 3) a solução deve ser interpessoal ou negociada intersubjetivamente; 4) a tecnologia pode desempenhar um papel fundamental neste processo de resolução de problemas interpessoais, facilitando a comunicação entre os participantes; 5) os alunos devem estar alertas para os problemas adicionais que surgem quando eles propõem uma solução preliminar para uma situação real; eles devem ser encorajados a lidar com esses subprodutos de seu processo intersubjetivo; 6) o processo de solução também deve exigir uma abordagem interdisciplinar e deve, se possível, envolver pessoas com diferentes habilidades / conhecimentos; 7) A solução desses problemas do mundo real deve permitir prazos prolongados de reflexão; a complexidade situacional raramente pode ser resolvida em poucos minutos; 8) esses problemas muitas vezes suscitam várias soluções, que devem competir entre si; não deve haver respostas "corretas", mas diferentes graus de viabilidade; 9) deve ser necessário distinguir entre as informações relevantes e informações de pouca utilidade: problemas do mundo real geralmente são acompanhados de informações supérfluas tal discernimento faz parte das habilidades que os estudantes devem desenvolver; 10) a resolução de problemas do mundo real deve facilitar a tomada de consciência dos valores pessoais próprios e preconceitos do aprendiz, e como eles podem afetar o resultado do trabalho em grupo. Esta lista de atributos ideais ilustra como a autenticidade contextual está completamente relacionada com os outros componentes do modelo de Interatividade Colaborativa. Tomados isoladamente, nenhum deles desenvolve ao máximo o potencial de aprendizagem socioconstrutivista; é preciso criar ambientes de aprendizagem em que os quatro elementos estejam presentes.

Como mencionado anteriormente, as habilidades desenvolvidas pela abordagem socioconstrutivista de ensino de gestão são relevantes não só no ambiente escolar, mas também, e acima de tudo, na vida profissional dos estudantes. Em um contexto hipercompetitivo e hiperconectado, as organizações hierárquicas aproximam-se cada vez mais de estruturas em redes de aprendizagem, em uma tentativa de aumentar a sua capacidade de agilizar a adaptação de novos produtos e processos às mudanças constantes do mercado. Segundo Robins e Webster (1999, p. 203-204), essas mudanças estão ocorrendo porque

[...] Burocracias hierárquicas perdem muito do seu propósito quando redes de informação facilitam a tomada de decisão e a implementação colaborativa de soluções (e quando o fator velocidade é mais imperativo do que nunca). [...] Se por um lado os cortes de níveis hierárquicos são feitos por razões de economia e porque as tecnologias facilitam a comunicação em rede, por outro lado os herdeiros dessas estruturas flexíveis têm muito mais poder.

Em suma, há um consenso na literatura de que os casos favorecem um ambiente de aprendizagem lúdico e rico, complementando a aula tradicional com atividades dinâmicas baseadas no inquérito individual e na discussão coletiva. Trata-se de uma excelente oportunidade de desenvolver os princípios da manipulação, reflexão e colaboração em um contexto autêntico. A seção seguinte explora as competências cognitivas envolvidas nesse processo.

\section{Competências cognitivas desenvolvidas pelo Método Caso}

Os benefícios que os alunos obtêm a partir de estudos de caso são diretamente proporcionais aos esforços de preparação que eles estão dispostos 
a fazer. A preparação básica envolve a leitura do caso, pelo menos duas vezes individualmente, antes de formarem grupos de discussão (BUCIUNIENE, 2012; DHAR; DHAR, 2007). Durante a primeira leitura (também chamada de "visão geral"), os alunos são encorajados a simplesmente folhear o texto para ter uma perspectiva geral do que o caso trata, quem são os protagonistas e qual é o principal problema. Durante uma segunda leitura, mais cuidadosa (também chamada de "leitura ativa"), os alunos devem fazer anotações, destacar indícios e procurar elementos que podem responder a eventuais perguntas sobre o problema. Esses elementos coletados individualmente devem ser discutidos em grupo durante as fases de análise colaborativa do caso. Essas são as atividades que, junto com a discussão plenária em sala de aula e trabalhos extraclasse, formam a essência do processo de aprendizagem ativa em estudos de caso de gestão.

Naumes e Naumes (2012) apresentam uma excelente síntese dos processos mentais relevantes que ocorrem durante a análise de um estudo. De acordo com eles, há oito domínios de competências cognitivas que são estimuladas pelo método caso:

- Foco: a capacidade de definir os problemas e definir metas;

- Coleta de informações: tomar nota de dados disponíveis ou procurar dados adicionais;

- Memorização: habilidades de codificação e recordação de informações críticas;

- Organização: comparar, classificar, ordenar e representar a informação;

- Análise: identificar atributos e componentes do problema, estabelecendo relações e padrões, identificando ideias principais;

- Geração de cenários: a partir de inferências, previsões e projeções;

- Integração: capacidade de resumir e reestruturar informações;

- Avaliação: capacidade de estabelecer critérios e verificá-los.

Uma abordagem mais visualmente estruturada de como essas habilidades são desenvolvidas em estudos de caso é fornecida por Lima (2003), baseado em um estudo genérico do Departamento de Educa- ção de Iowa (1989). A Figura 2 ilustra esse conceito de "modelo de raciocínio integrado" (MRI).

Figura 2 - Modelo de Raciocínio Integrado de aprendizagem com estudos de caso

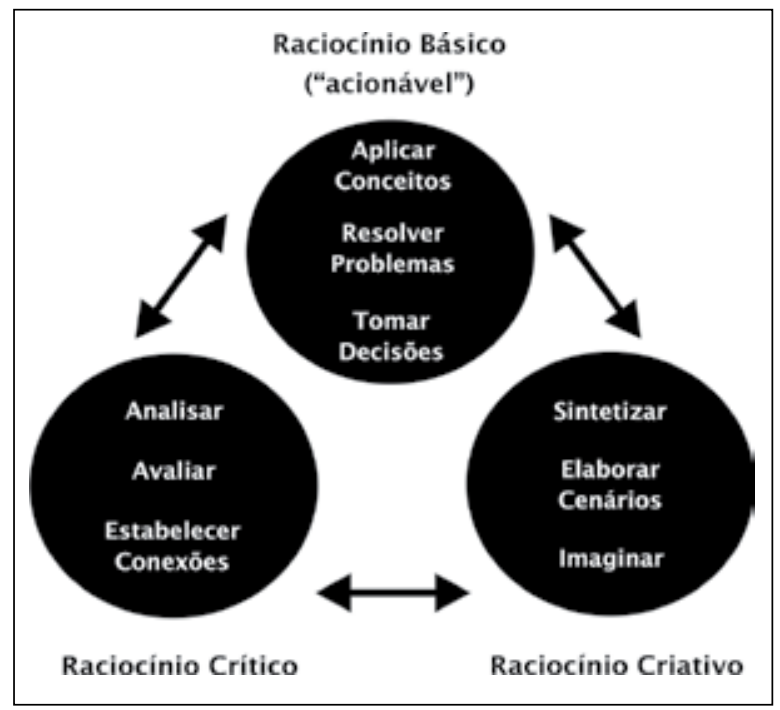

Fonte: Adaptado de Lima (2003).

Esse modelo assume que o objetivo final da educação em gestão é fazer com que os alunos desenvolvam o que pode ser chamado de "raciocínio acionável" (a capacidade de aplicar conceitos, resolver problemas e tomar decisões). Tal habilidade requer competências de raciocínio crítico (analisar, avaliar, estabelecer conexões) e criativo ( sintetizar, elaborar cenários / imaginar).

Cada uma das três competências de raciocínio básico nos moldes do MRI pode ser associada com os tipos de casos descritos por Ellet (2007). Assim, casos do tipo "problema" reforçam as habilidades de "resolver" (compreender o problema, pesquisar e formular o problema, encontrar alternativas, escolher uma solução e facilitar a sua aceitação); casos de avaliação estimulam o desenvolvimento da capacidade de "aplicar conceitos" (imaginar objetivos, conceber um produto / serviço, avaliá-lo e reconcebê-lo), enquanto os casos decisórios incidem sobre as competências de tomada de decisão (identificar um problema, gerar alternativas, avaliar a consequências, fazer escolhas e avaliá-las).

O pilar do "raciocínio crítico" do modelo MRI abrange as competências de análise (reconhecer padrões, classificar, identificar pressupostos e 
ideias principais, encontrar sequências), avaliação (avaliar informações, determinar critérios de priorização, reconhecer falácias, verificar) e estabelecimento de conexões (comparar / contrastar, pensar logicamente, inferir de forma dedutiva e indutiva, identificar relações causais).

Por fim, o componente "raciocínio criativo" do modelo MRI é baseado na capacidade de sintetizar (pensar analogicamente, resumir, formular hipóteses, planejar), elaborar cenários e imaginar (prever, especular, visualizar, expandir ideias).

\section{Limitações do Método Caso}

O método caso comporta, evidentemente, várias limitações. Em primeiro lugar, ele não deve ser considerado como uma panaceia que vai resolver todos os problemas da educação em gestão. Ele não deve, absolutamente, ser usado como única abordagem pedagógica; sendo na sua maioria de natureza indutiva, os casos devem ser combinados com abordagens dedutivas como palestras e discussões de livros didáticos convencionais. Listamos a seguir uma série de limitações citadas na literatura, muitas das quais estão claramente relacionadas com a natureza indutiva dos casos (BUCIUNIENE, 2012; DHAR; DHAR, 2007; JACKSON, 2011; LIMA, 2003; SKUDIENE, 2012):

- o realismo dos casos é limitado, na medida em que contrariamente aos protagonistas da narrativa, os alunos não sofrerão as consequências de decisões ou diagnósticos mal feitos;

- gerentes da vida real reúnem as "peças do quebra-cabeça" através de interações longas e árduas com a organização e o seu ambiente; eles não vão encontrar o problema e as informações necessárias para resolvê-lo prontamente disponíveis em uma dúzia de páginas com quadros cuidadosamente preparados. A busca da informação é uma das competências que são muito raramente exploradas em estudos de caso (no entanto, essa deficiência pode ser parcialmente compensada quando se escrevem casos com informações deliberadamente escassas e se incentiva os alunos a usar a Internet e bases de dados de gestão para reunir os elementos necessários para o diagnóstico);

- ao se concentrar exclusivamente em uma questão (ou poucos pontos), os casos tendem a simplificar a interdependência dos problemas de gestão. Um problema de marketing raramente é desconectado dos outros domínios de conhecimento de negócios, como finanças, recursos humanos e produção. Isto pode levar ao que Jackson (2011) chama de síndrome de resolver "o problema errado com grande precisão";

- o caso geralmente "congela" um problema de negócio no tempo e no espaço, o que geralmente inibe o pensamento a longo prazo;

- por serem baseados em fatos reais, casos são construídos a partir de entrevistas com os protagonistas. Eles são, frequentemente, propensos ao que Jackson (2011) chama de "viés da retrospectiva" (hindsight bias), ou seja, a tendência a olhar para o passado de forma superotimista ou pessimista;

- casos em papel sofrem de todas as limitações inerentes à tecnologia da imprensa, inventada no século XV. Eles são difíceis de atualizar, não são muito interativos e não têm recursos multimídia ou mecanismos intrínsecos de colaboração. Na era das mídias sociais, os casos precisam ser adaptados para capturar a versatilidade, acessibilidade e riqueza de recursos midiáticos oferecidos pela Internet.

O último aspecto é justamente o que justifica repensar a abordagem de casos no contexto tecnológico moderno. Na seção final, a seguir, vamos explorar como essas competências tipicamente associadas com a abordagem clássica de Harvard podem ser enriquecidas em dois ambientes de aprendizagem mediados tecnologicamente para facilitar a discussão de casos.

\section{Repensando o método caso para o século XXI: duas experiências}

\section{O experimento Panteon}

Dez anos atrás, um dos autores, Lima (2003), defendeu sua tese de doutorado sobre o tema $\mathrm{Po}_{\mathrm{O}}$ 
tencial de Suporte Cognitivo das Interfaces Hipertextuais Dinâmicas: o Sistema Panteon como uma Alternativa aos Casos tipo Harvard. Sua hipótese principal era de que as propriedades de armazenamento de informação, processamento e distribuição inerentes às interfaces web poderiam facilitar o uso de habilidades críticas e criativas durante a análise organizacional baseada em estudos de caso, seja para fins de planejamento estratégico ou de ensino / aprendizagem. Partindo desse pressuposto, Lima criou a Interface Panteon, uma ferramenta hipertextual para análise organizacional com base em estudos de caso. A plataforma consiste de um motor de busca que recupera depoimentos de vários atores envolvidos direta ou indiretamente com um problema organizacional (protagonistas, mas também clientes, fornecedores, colegas de outros departamentos da empresa, concorrentes etc.) Estas citações diretas podem ser navegadas de acordo com vários critérios: estrutura organizacional (marketing, finanças, recursos humanos etc.), palavra-chave (declarações contendo a palavra "concorrentes" ou "crise"), as diferentes situações-problema (o problema de fluxo de caixa, uma questão de motivação, uma crise insatisfação do cliente etc.). Os critérios de busca / navegação podem também abranger as categorias de qualquer modelo dado de análise (SWOT, Rivalidade Ampliada de Porter, Marketing Mix etc.).

Esses critérios podem ser combinados para satisfazer uma consulta particular; assim, por exemplo, pode-se perguntar: "o que é que as pessoas do departamento de vendas têm a dizer sobre as ameaças do problema FLUXO DE CAIXA?". Os usuários podem, em seguida, comentar o que pensam de cada percepção ou declaração resultante de suas consultas. Equipes de estudantes podem usar a ferramenta para compilar esses comentários e comparar suas diferentes percepções sobre as declarações fundamentais. Assim, um diagnóstico colaborativo é facilitado pelo sistema. Lima concluiu que esta abordagem não linear assistida por computador pode melhorar e estimular o pensamento crítico e criativo ainda mais do que a abordagem tradicional de Harvard.

A fim de testar o protótipo Panteon e sua premissa subjacente, Lima realizou uma série de experimentos de observação participante em que a interface foi usada tanto em ambientes acadêmicos quanto corporativos, seguidos por grupos focais, discussões para debater e lançar luz sobre os resultados obtidos.

Como fundamentação teórica, tanto para a criação quanto aplicação de Panteon, ele explorou as possíveis relações entre os campos da tecnologia de comunicação e habilidades cognitivas. Ele discutiu como, na "Era da Informação", a gestão do conhecimento dentro das organizações depende tanto da interação entre as pessoas como de dispositivos de mídia que podem ajudar a minimizar os problemas relacionados com o armazenamento, processamento e distribuição da informação.

Depois de avaliar as experiências com Panteon, ele concluiu que a flexibilidade dos seus mecanismos de processamento de informação poderia realmente enriquecer a análise organizacional baseado no método de estudo de caso, tanto para o ensino / aprendizagem como para fins de planejamento estratégico. Os experimentos mostraram que, quando usados em um contexto no qual a interação, reflexão e conversa são estimulados através de múltiplas perspectivas, interfaces web podem facilitar o desenvolvimento de habilidades críticas e criativas em profissionais e estudantes. Pode-se encontrar uma síntese da experiência Panteon (com fotos de um protótipo de interface) no Journal of Educational Computing Research (LIMA, KOEHLER; SPIRO, 2004).

\section{Usando mídia social para estimular o racio- cínio crítico e criativo: a experiência Organixis}

Uma experiência mais recente (LIMA et al, 2014) em nossa escola de gestão (EMLV, Paris) pode lançar luz sobre os potenciais benefícios e dificuldades ao se combinar princípios de aprendizagem socioconstrutiva com as ferramentas de mídia social, como discutido anteriormente. Usando o Google Sites, Youtube e Facebook, criamos um estudo de caso interativo que facilita a criação de conteúdo enriquecido com vídeos, imagens e texto (comentários, links, tags etc.).

O caso, que chamamos de "Organixis", descreve uma empresa de software fictícia que produz jogos para telefones celulares. Foi necessário o trabalho de uma dúzia de professores de três departamentos (finanças, marketing e recursos humanos) durante 
cerca de três meses para criar uma descrição detalhada dos problemas da empresa em cada domínio, incluindo links para recursos externos, vídeos embutidos com temas relacionados e gráficos conceituais para ajudar os alunos a entender como cada "árvore" cabe na "floresta" em geral.

O site para este caso (em francês), construído com ferramentas Google do site, está disponível em https://sites.google.com/site/organixis2/. A abordagem pedagógica consistia em atribuir funções de consultor em finanças, recursos humanos ou marketing a cada um dos 80 alunos do quarto ano que participaram do experimento. Esta foi uma amostra de conveniência de estudantes que foram obrigados a participar de um seminário de empreendedorismo com duração de três dias. Como parte das atividades para esse seminário, decidimos criar um ambiente organizacional imersivo para confrontar os alunos com os problemas de lançamento de um novo produto. Os estudantes tiveram duas semanas para percorrer as dezenas de páginas do Google Sites, concentrando-se principalmente no seu "domínio de conhecimento" e, ao mesmo tempo, tentando obter uma visão geral dos problemas nos outros domínios. Eles foram convidados a colaborar à distância em fóruns específicos de discussão que foram criados usando uma página no Facebook, e eles foram incentivados a compartilhar suas ideias, materiais adicionais relativos a questões específicas ou problemas, links e vídeos sobre essa plataforma.

Após as duas semanas de colaboração à distância, eles se encontraram em quatro classes distintas de 20 alunos para uma maratona de 8 horas de análises e recomendações. Como primeiro passo, em cada aula, os alunos foram convidados a "interrogar" o que aprenderam em seus domínios de especialização durante as duas semanas de "colaboração assíncrona". Os especialistas em finanças, marketing e RH expuseram diante da classe as principais questões que identificaram ao navegar o seu domínio individualmente; uma vídeo-projeção do conteúdo compartilhado via Facebook ajudou a sintetizar os principais pontos discutidos on-line.

Uma vez que todas as questões-chave foram identificadas por via oral, os facilitadores em cada turma formaram 5 grupos de 4 especialistas (um em finanças, um em recursos humanos, um em marketing estratégico e um em marketing tático) e deram-lhes três "cartões Metaplan" (codificados por cores dos cartões que podem ser facilmente ligados a uma parede ou folha flipchart). Pediu-se aos estudantes que descrevessem os três problemas principais enfrentados por Organixis em todos os domínios. Os 12 problemas foram publicados em folhas de flipchart colados à parede ao redor da sala. Quando o facilitador identificava temas comuns, ele ou ela os agrupava em um único cluster temático. Em seguida, cada aluno recebeu três mini-post-its (pequenos autoadesivos quadrados coloridos) que eles poderiam usar para "votar" nos três problemas que, pessoalmente, achavam que eram os mais relevantes. Como resultado, o "pensamento coletivo" de cada classe tornou-se claramente visível.

Finalmente, demos 3 horas a cada grupo para preparar um diagnóstico detalhado dos problemas, como eles se inter-relacionam e como eles poderiam ser resolvidos. Na parte da tarde os quatro grupos apresentaram soluções e debateram a sua implementação. Após essas atividades, realizamos entrevistas e conversas informais aleatórias com alguns participantes da amostra sobre os desafios e oportunidades associados a este tipo de abordagem pedagógica. Também revisitamos os tópicos de discussão reais no Facebook sobre o caso e sua implementação.

Alguns extratos dos insumos Facebook dos grupos amostrados são reproduzidas abaixo (traduzidos da página Organixis Facebook em francês). Estas reações ilustram como os princípios de Interatividade Colaborativa em torno de problemas autênticos usando ferramentas de mídia social podem promover algumas das competências de pensamento crítico / criativo descritos anteriormente:

\section{Analisar:}

Concordo com você, Janaína. Além disso, os homens entre 30 e 40 podem se dar ao luxo de gastar mais em jogos do que os outros alvos. Devemos tentar fazer um estudo sobre que tipo de jogos pode agradá-los... para melhor atender as suas expectativas. No entanto, também temos de tentar de novo encontrar um jogo que poderia apelar para 'adolescentes' porque Vampyx não foi um sucesso. 


\section{Avaliar:}

Sim, eu concordo. Mas a respeito da escolha do produto, não estamos falando bastante sobre o marketing operacional? Bem, podemos dar-lhes ideias. Quanto à segmentação, parece que os adolescentes e jovens de 30-40 anos são os dois grupos de idade para se concentrar e para explorar.

\section{Estabeler conexões:}

É verdade que não há muitos jogos concebidos para as mulheres. .. Ainda assim, vemos mais e mais mulheres jogando com consoles ... Como o Wii. Os consoles desenvolveram jogos com base nas necessidades das mulheres e conquistaram um monte de clientes. Por que não tentar fazer o mesmo com os jogos no celular?

\section{Sintetizar:}

Nossas sugestões: encontrar novos critérios de segmentação; modificar as faixas etárias do alvo; encontrar o equilíbrio certo de recursos nos segmentos-alvo; melhorar a comunicação externa (promoção através das redes sociais).

\section{Elaborar / Imaginar:}

Para os 'adolescentes', poderíamos fazer uma competição com prêmios para os vencedores... poderíamos estimulá-los a jogar mais. E sobre o alvo de 30-40 anos de idade, prefiro sugerir jogos que os lembrem do que faziam quando eles eram jovens; poderíamos fazer novas versões de jogos antigos.

Essas declarações amostrais validam claramente as suposições feitas relativas ao potencial de raciocínio crítico e criativo das ferramentas on-line para a aprendizagem por casos. Tais indícios qualitativos parecerem confirmar o potencial de uso de ferramentas de colaboração on-line para a aprendizagem socioconstrutivista. No entanto, entrevistas e conversas informais que tivemos com alunos e professores após a experiência revelam um cenário mais complexo. Embora tenha havido uma atitude geral positiva em relação a esse tipo de ferramenta de ambos os lados, havia também uma sensação de que o esforço para criar e coordenar tais ambientes virtuais de aprendizagem é desproporcional aos benefícios reais. De fato, várias das objeções puderam ser identificadas entre professores e alunos.
Do lado dos professores, eles sentiram que as habilidades semelhantes de raciocínio crítico e criativo podem ser mais facilmente estimuladas com métodos tradicionais de discussão de estudos de caso em sala de aula, sem a ajuda de tecnologia baseada na web. Eles também apontaram que a preparação de casos multimídia para ensino à distância baseado em uma empresa fictícia é tanto mais exigente e menos autêntica do que o uso do mundo real, como acontece nos casos baseados em papel. Ainda que estivessem dispostos a colaborar virtualmente, eles argumentaram que o esforço de coordenação necessário para criar uma abordagem multidisciplinar consistente na web torna essa abordagem impraticável como um método de ensino regular. Além disso, eles argumentaram que nem todos eles têm as habilidades técnicas para prosperar nesse ambiente. Muito poucos entre os professores se declararam prontos a repetir a experiência por conta própria ou a incorporar essa colaboração baseada na Web como um elemento de rotina de seus cursos.

Do lado dos estudantes, eles reconheceram que, embora seja "legal" simular ambientes de ensino à distância com navegação não linear e recursos multimídia, a realidade é que a colaboração em grupo face a face lhes é muito mais fácil / familiar. Houve uma sensação de que "barreiras artificiais de tempo / espaço" foram criadas com a finalidade de viabilizar o experimento durante as quatro semanas de colaboração à distância. Os estudantes também notaram que o caráter "fictício" do caso (que facilitou o desenvolvimento da abordagem interdisciplinar) tornou-o menos autêntico do que os cenários reais habitualmente tratados. Essa observação reforça a importância do princípio elementar de Harvard de sempre usar situações reais.

Apesar desses inconvenientes, os componentes de "nova geração" do experimento foram bastante apreciados. Os estudantes gostaram da possibilidade de discutir o caso no Facebook, apreciaram os componentes multimídia do caso e a navegação de um espaço de informação não linear. Eles também entenderam que há uma tendência para a colaboração baseada na web nos ambientes empresariais modernos e desejaram que continuássemos a fazer experiências com ferramentas on-line para replicar esse ambiente. Os estudantes mostraram-se bas- 
tante consciente dos limites do formato de aula tradicional e manifestaram o desejo de evoluir para um ambiente mais participativo, baseado em tecnologias de aprendizagem semelhantes às criadas em torno do caso virtual Organixis.

\section{Conclusões}

Ainda que com perspectivas promissoras, as experiências Panteon e Organixis nos mostraram que uma das vantagens do método caso tradicional reside justamente na sua simplicidade. Os professores, em particular, são muitas vezes resistentes a curvas acentuadas de aprendizagem típicas de novos projetos de tecnologia; eles preferem ter uma solução pronta para uso, tipo turn-key, sob a forma de casos impressos com notas de ensino. À medida que a Geração Y amadurece, no entanto, esse cenário pode mudar. Outras tentativas de adaptação do método caso para a web estão em andamento, como, por exemplo, a plataforma Caso 3.0 de Jackson (2011). Naumes e Naumes (2012) discutem a possibilidade de usar ferramentas de colaboração como wikis (plataformas web, como o Google Drive ou Microsoft 365) para trabalhar à distância antes de vir à aula para discutir os resultados. Em suas palavras:

Os alunos podem desenvolver a sua análise de casos em grupos de wikis, chegando à classe já preparados para comparar, criticar e construir sobre essas análises. Como alternativa, o período de aula poderia incidir sobre a criação de uma análise comum, com fóruns de discussão ou wikis sendo usados depois da aula para os alunos desenvolverem recomendações. (NAUMES; NAUMES, 2012, p. 158).

Esses são, talvez, estágios iniciais de uma tendência irreversível. Acreditamos que, eventualmente, os benefícios cognitivos do uso de interfaces web para análise de estudo de caso e à natureza colaborativa da Mídia Social irão criar alternativas viáveis para essa antiga tradição em educação empresarial.

No curto prazo, os depoimentos dos participantes em nossa experiência recente nos dão uma perspectiva ambígua. Os professores relutam em mudar a sua pedagogia tradicional, que consideram mais produtiva e rentável, enquanto os alunos descobrem que algumas das barreiras de espaço / tempo impostas são um tanto artificiais, preferindo ainda trabalhar face a face. Apesar dessas objeções, a maioria dos alunos apreciou a natureza não linear e os recursos multimídia do ambiente de aprendizagem inovador e desejaram poder desenvolver mais tais atividades. Isto sugere que o futuro da aprendizagem socioconstrutivista de base tecnológica é muito promissor, apesar de sua infância difícil.

Finalmente, deve-se notar que este estudo está ainda na sua fase exploratória. Baseia-se nos insights de mais de uma década obtidos com o Panteon, assim como na observação de uma amostra limitada em uma escola de gestão de Paris. Mais pesquisas qualitativas e quantitativas devem ser desenvolvidas para entender como fazer o melhor uso da Interatividade Colaborativa no ensino superior.

\section{REFERÊNCIAS}

ABELL, D. What makes a good case? ECCHO - The Newsletter of the European Case Clearing House, v. 17, n. 1, p. 4-7, 1997.

BRULHART, F. Les 7 points clés du diagnostic stratégique: avec la méthode des cas. Paris: Eyrolles, 2009.

BUCIUNIENE, I. Teaching with cases: what makes the teaching - learning process efficient? In: AMMERMAN, P. Et al. (Ed.). The case study method in business education. Poznan : Bogucki Wydawnictwo Naukowe, 2012.

DHAR, U.; DHAR, S. Case method in management education training. New Delhi : Excel Books, 2007.

ELLET, W. The case study handbook. Boston, MA: Harvard Business School Press, 2007.

GRAGG, C. I. Because wisdom can't be told. In: MCNAIR, M. P. (Org.). The case method at the Harvard Business School. New York: McGraw-Hill, 1954. p. 6-14.

GREER, J. Et al. Integrating cognitive tools for peer help: the intelligent intranet peer help-desk project. In: LA- 
JOIE, S. (Org.). Computers as cognitive tools. Vol. II. Mahwah: Lawrence Erlbaum Associates, 2000. p. 69-96.

HEATH, J. Teaching and writing case studies: a practical guide. Cranfield: The Case Centre (formerly European Case Clearing House), 2006.

IOWA DEPARTMENT OF EDUCATION. A guide to developing higher order thinking across the curriculum. Des Moines, IA: Department of Education, 1989.

JACKSON, G. Rethinking the case method. Journal of Management Policy \& Practice, v. 12, n. 5, p. 142-164, 2011.

JONASSEN, D. Et al. Learning with technology: a Constructivist perspective. Upper Saddle River: Merril, Prentice Hall, 1999.

LIMA, M. Potencial de suporte cognitivo das tecnologias interativas de comunicação: desenvolvimento de uma interface hipertextual dinâmica para análise organizacional baseada em estudos de casos. 2003. Tese (Doutorado em Comunicação) - Faculdade de Comunicação, Universidade Federal da Bahia (UFBA), Salvador, 2003.

LIMA, M. Et al. Social media as a learning resource for business students of the 'Net Generation': using active learning principles to empower creative and critical thinking. International Journal for Quality in Higher Education Institutions, 2014. In print.

LIMA, M.; KOEHLER, M. ; SPIRO, R. Collaborative interactivity and integrated thinking in Brazilian business schools using cognitive flexibility hypertexts: the Panteon project. Journal Eductional Computing Research, v. 31, n. 4, p. 371-406, 2004.

LUCENA, C.; FUKS, H. A educação na era da internet. Rio de Janeiro: Clube do Futuro, 2000.

MASETTO, M. T. Mediação pedagógica e o uso da tecnologia. In: MORAN, J. M.; MASETTO, M. T. ; BEHRENS, M. A. (Org.). Novas tecnologias e mediação pedagógica. São Paulo: Papirus, 2001. p. 133-173.

MATTA, A. Procedimentos de autoria hipermídia em redes de computadores: um ambiente mediador para o ensino-aprendizagem de História. 2001. Tese (Doutorado em Educação) - Faculdade de Educação, Universidade Federal da Bahia (UFBA), Salvador, 2001.

NAUMES, W.; NAUMES, M. J. The art \& craft of case writing. Armonk, New York: M. E. Sharpe, 1999.

NAUMES, W.; NAUMES, M. J. The art \& craft of case writing. 3. ed. Armonk, New York: M. E. Sharpe, 2012.

PILKIENE, M. How a faculty should prepare for a teaching with cases. In: AMMERMAN, P. Et al. (Ed.). The case study method in business education. Poznan : Bogucki Wydawnictwo Naukowe, 2012.

PITT, L. Et al. Case teaching in the age of technological sophistication. Journal of The Academy Of Business Education, p. 11-28, 2012.

ROBINS, K.; WEBSTER, F. Times of the technoculture: from the information society to the virtual life. Londres: Routledge, 1999.

SANDHOLTZ, J. H. Teaching with technology. New York: Teachers College Press, 1996.

SELINGER, M. Setting authentic tasks using the internet in schools. In: LEASK, M. (Org.). Issues in teaching using ICT. Londres: Routledge, 2001. p. 96-105.

SKUDIENE, V. Case method education. In: AMMERMAN, P. Et al. (Ed.). The case study method in business education. Poznan: Bogucki Wydawnictwo Naukowe, 2012.

SPENCER, K. The psychology of educational technology and instructional media. United Writers Press, 1991.

SRINIVASAN, Shiva Kumar. Et al. What is the future of the case method in management education in India? Vikalpa, v. 30, n. 4, p. 92-131, Oct./Dec., 2005.

TOBIN, K. Constructivism in science and education: moving on. In: PHILLIPS, D. C. (Org.). Constructivism in education: opinions and second opinions on controversial issues. Chicago: National Society for the Study of Education, 2000. p. 227-253.

WILLIAMSON, T. Enhancing the quality of the student learning experience through the case method. In: AM- 
MERMAN, P. Et al. (Ed.). The case study method in business education. Poznan : Bogucki Wydawnictwo Naukowe, 2012.

YOUNG, M. F. Tecnología interactiva para la enseñanza: integración de una lección interactivaen videodisco con las actividades tradicionales de la clase. In: LIMÓN, A. A. Et al. (Org.). Nuevos medios, viejos aprendizajes: las nuevas tecnologías en la educación. México, DF: Universidad Iberoamericana, 1995. p. 83-102.

Recebido em: 16.07.2014

Aprovado em: 01.10.2014 